\title{
2 On the effect of initial drying techniques on essential oil composition, phenolic compound and antioxidant properties of anise (Pimpinella anisum L.) seeds
}

\section{Iness Bettaieb Rebey ${ }^{1,2}$. Soumaya Bourgou ${ }^{1}$. Sofiene Ben Kaab ${ }^{1} \cdot$ Wissem Aidi Wannes ${ }^{1} \cdot$ Riadh Ksouri $^{1}$. Moufida Saidani Tounsi ${ }^{1} \cdot$ Marie-Laure Fauconnier $^{2}$}

Received: 28 May 2019 / Accepted: 30 September 2019

๑) Springer Science+Business Media, LLC, part of Springer Nature 2019

\begin{abstract}
The effect of drying methods (sun, oven and shade drying) on aniseeds was investigated in terms of their essential oils, phenolics and antioxidant activities. The optimum yield of essential oil was found in shade drying $(2.62 \%)$. Fourteen volatile compounds were determined in all samples with variation of the main component proportions depending on drying methods. Thus, trans-anethole $(84.21 \%)$ and estragole $(3.82 \%)$ proportions significantly increased in shade drying. The highest total phenol and flavonoid contents of aniseeds were recorded in shade drying $(42.70 \mathrm{mg}$ of GAE/g and $53.55 \mathrm{mg}$ of QE/g, respectively) while the lowest contents in oven drying at $60^{\circ} \mathrm{C}(31.15 \mathrm{mg}$ of GAE/g and $46.20 \mathrm{mg}$ of QE/g, respectively). In all drying methods, naringin (41.04-43.76\%), chloroginic acid (23.13-27.19\%) and rosmarinic acid (12.26-15.95\%) were the predominant phenol compounds. Although shade drying increased the antioxidant activity, aniseed extracts exhibited higher radical scavenging $\left(\mathrm{IC}_{50}=10.15 \mu \mathrm{g} / \mathrm{mL}\right)$, reducing power $\left(\mathrm{EC}_{50}=187.24 \mu \mathrm{g} / \mathrm{mL}\right)$ and chelating $\left(\mathrm{IC}_{50}=6.85 \mathrm{mg} / \mathrm{mL}\right)$ capacities than essential oils $\left(\mathrm{IC}_{50}=114.87 \mu \mathrm{g} / \mathrm{mL}, \mathrm{EC}_{50}=548.05 \mu \mathrm{g} / \mathrm{mL}\right.$ and $\mathrm{IC}_{50}=58.65 \mathrm{mg} / \mathrm{mL}$, respectively). In conclusion, Shade drying method was found to enhance essential oils, phenols and antioxidant activities in aniseeds.
\end{abstract}

\section{Keywords Pimpinella anisum L. · Sun drying · Oven drying $\cdot$ Shade drying $\cdot$ Essential oil $\cdot$ Antioxidant}

\section{Introduction}

Most herbs and spices are marketed in dry form, since they contain a high percentage of water when fresh and can suffer alterations in their composition [1]. Thus, drying is the most common method for preserving foods and the widespread step for processing medicinal herbs to reduce microbial growth, cost of packaging, and weight and bulk of plants for cheaper transport and storage [2]. It is also used to prepare the starting material for further processing such as essential oil. The effects of different drying methods on the structure, shape and compositions of material are different because

Iness Bettaieb Rebey

bettaiebrebey@yahoo.fr

1 Laboratory of Medicinal and Aromatics Plant, Biotechnology Center of Borj-Cedria, BP 901, 2050 Hammam-Lif, Tunisia

2 General and Organic Chemistry-Volatolomics, Gembloux Agro-Bio Tech, University of Liège, Passage des Déportés 2, 5030 Gembloux, Belgium of the differences in characteristics, mechanism and conditions of drying process [2]. Thus, drying of aromatic herbs is critical because organoleptic and sensory characteristics as well as essential oil composition and content are all indicators of quality and are reported to be influenced by drying methods [3, 4]. In case of spices drying can produce changes in their flavour and appearance, and both these aspects are important quality factors with an impact on how consumers accept the spices [1]. As a result, the choice of the drying method depends on various factors, such as the type of product, availability of unique dryers, the desired attributes of the desiccated product, capital costs, and the energy consumed during drying. In agricultural crops, it is important to iden-AQ2 tify appropriate time for drying because excessive decrease of humidity results in decreased quality and quantity of final crops [5]. It is also worth noting that the extent of degradation of bioactive compounds observed for a specific drying method largely depends on the taxonomic family of herbs. This is evidenced by a past study concerning the drying of various herbs, which showed that the lowest degradation of phenolic compounds was observed for herbs belonging to

\begin{tabular}{|l|l|l|l|l|}
\hline Journal : Large 11694 & Article No : 284 & Pages : 9 & MS Code : 284 & Dispatch : 4-10-2019 \\
\hline
\end{tabular}


the taxonomic family Apiaceae (parsely, lovage) followed by herbs from Brassicaceae (rocket) and the highest degradation was observed for Lamiaceae (mint, oregano, basil) [6]. Sun drying is a traditional method used for the drying of agricultural products and, till today, remains a widely used drying technique. Although sun drying is a low-cost drying method, it has various disadvantages: difficulty in controlling drying rate, no uniform drying, allows the contamination of product by the growth of fungi and bacteria due to the slow drying rate [7]. To eliminate direct exposure to sunlight, shade drying has been introduced to produce higher-quality products than sun drying.

Pimpinella anisum L. has been widely used as a culinary ingredient as well as traditional remedies for the treatment of different disorders in the folk medicine systems of different civilizations. Anise essential oil is mainly constituted by anethole, an aromatic substance that appears as the major compound of the oil, usually corresponding to more than $80 \%(w / w)$ of the oil [8-10]. Extracts and/or essential oils obtained from this species have been proven to have various biological activities such as carminative, expectorant, antiseptic, anti-depressant, anti-spasmodic, antifungal, antibacterial, antioxidant, insecticidal, and diuretic $P$. anisum L. has long been used as a folk remedy for the treatment of asthma, bronchitis, cancer, cholera, colic, cough, insomnia, and nausea by the local people [11]. However, chemical and biological characteristics of aniseeds essential oil and extracts are often influenced by ripening stage, provenance, extraction methods...etc. [12, 13].

Although the biochemical profiles of aniseeds are well described, there is no published literature on the effect of drying techniques on the essential oil yield, phenolic content and antioxidant activities of aniseeds ( $P$. anisum $\mathrm{L}$ ). Thus, the objective of the work described herein was to determine the possible effect of drying methods including shade drying, sun drying and oven drying on the chemical profile, and the antioxidant ability of $P$. anisum $L$. seeds.

\section{Materials and methods}

\section{Plant material and drying conditions}

Mature aniseeds (P. anisum L.) were harvested in June 2017 from the region of Korba in the northeast of Tunisia; latitude $36,34038.22^{\prime}(\mathrm{N})$; longitude 10,510 29.63' (E) and the altitude is $637 \mathrm{~m}$. Plant identification was carried by Professor Abderrzek Smaoui (Biotechnology Center in Borj-Cedria Technopole, Tunisia). A voucher specimen was deposited at the herbarium of the Laboratory of Bioactive Substances, Biotechnology Center in Borj-Cedria Technopole under the "BC2011-2002" number. After harvest, seeds were divided into 3 groups and were dried by using one of the following methods: (1) Oven drying (OD); (2) Sun drying (SD) and (3) Shade drying $(\mathrm{ShD})$. In brief, oven drying was conducted in a ventilated oven (Nüve FN 400) at $65^{\circ} \mathrm{C}$ for 3 days. In the case of sun and shade drying, $1 \mathrm{~kg}$ of seeds was arranged on $1 \mathrm{~m}^{2}$ of area for 4 and 10 days, respectively. Open air temperature was about $27^{\circ} \mathrm{C}$ and the shade one was about $18^{\circ} \mathrm{C}$. Before drying experiments, initial moisture content of the seeds was determined. The drying methods employed in each of these methods were selected after conducting trials to achieve a percentage moisture content of $<10 \%$ (w/w).

\section{Essential oil extraction of aniseeds}

Aniseeds were finely ground in an electric grinder (IKAWERK. Type: A: 10). Triplicate samples of $30 \mathrm{~g}$ were subjected to hydrodistillation in $0.5 \mathrm{~L}$ of deionized water using Clevenger apparatus for up to $4 \mathrm{~h}$, time which was necessary for a complete extraction.

\section{Gas chromatography (GC) analysis of aniseed essential oil}

GC analysis of volatile compounds was carried out according to Zaouali et al. [14] using an Agilent 6980 gas chromatograph equipped with a flame ionisation detector (FID) and an electronic pressure control (EPC) injector attached to HP-INNOWAX polyethylene glycol capillary column $(30 \mathrm{~m} 0.25 \mathrm{~mm})$. The flow of the carrier gas $\left(\mathrm{N}^{2}\right)$ was $1.6 \mathrm{~mL} \mathrm{m^{-1 }}$. The split ratio was $60: 1$. The analysis was performed using the following temperature program: oven temps isotherm at $35^{\circ} \mathrm{C}$ for $10 \mathrm{~min}$, from 35 to $205^{\circ} \mathrm{C}$ at the rate of $3{ }^{\circ} \mathrm{C} \mathrm{min}{ }^{-1}$ and isotherm at $205^{\circ} \mathrm{C}$ during $10 \mathrm{~min}$. Injector and detector temperature were held, respectively, at 250 and $300{ }^{\circ} \mathrm{C}$. One micro-liter of the sample (dissolved in hexane as $1 / 50 \mathrm{v} / \mathrm{v}$ ) was injected into the system. Individual peaks were identified by comparison of their retention indices relative to (C6-C22) n-alkanes with those of literature and/or with those authentic compounds available in our laboratory. Percentage compositions of samples were calculated according to the area of the chromatographic peaks using the total ion current.

\section{Gas chromatography-mass spectrometry (GC-MS) of aniseed essential oil}

The identification of the EOs was performed using a Hewlett Packard HP5890 series II GC-MS equipped with a HP5MS column (30 m $0.25 \mathrm{~mm})$. The carrier gas was helium at $1.2 \mathrm{~mL} \mathrm{~min}^{-1}$. Each sample $(1 \mu \mathrm{L})$ was injected in the split mode (1:20), the program used was isothermal at $70^{\circ} \mathrm{C}$, followed by $50-240{ }^{\circ} \mathrm{C}$ at a rate of $5{ }^{\circ} \mathrm{C} \min ^{-1}$, then held at $240{ }^{\circ} \mathrm{C}$ for $10 \mathrm{~min}$. The mass spectrometer was an HP 5972 and the total electronic impact mode at $70 \mathrm{eV}$ was used. 
The components were identified by comparing their relative retention times and mass spectra with the data from the library of EOs constituents, Wiley, Mass-Finder and Adams GC-MS libraries.

\section{Polyphenol extraction and analysis}

\section{Preparation of seed extracts}

Seed extracts were obtained by stirring $1 \mathrm{~g}$ of dry material powder with $10 \mathrm{~mL}$ of $80 \%$ acetone for $30 \mathrm{~min}$. Extraction was carried out using maceration at room temperature for $24 \mathrm{~h}$ followed by filtration through Whatman No. 4 filter paper and after evaporation to dryness. The yield (\%) of evaporated dried extracts was calculated as $100 \times$ DWextr/ DWsamp, where DWextr is the weight of extract after evaporation of solvent, and DWsamp is the dry weight of original sample. Samples were stored at $4{ }^{\circ} \mathrm{C}$ until analysis.

\section{Total phenolic amounts of seed extracts}

The total phenolic amount of the acetone extracts was determined by using Folin-Ciocalteu reagent (Merck), according to the procedure described by Dewanto et al. [15]. Briefly, $125 \mu \mathrm{L}$ of sample extract were dissolved in $500 \mu \mathrm{L}$ of distilled water and $125 \mu \mathrm{L}$ of Folin-Ciocalteu reagent. The mixture was shaken, before addition of $1.25 \mathrm{~mL}$ of $7 \%$ $\mathrm{Na}_{2} \mathrm{CO}_{3}$, adjusting with distilled water to a final volume of $3 \mathrm{~mL}$, and mixed thoroughly. After incubation in the dark for $90 \mathrm{~min}$, the absorbance at $760 \mathrm{~nm}$ was measured versus the prepared blank. Total phenolic amounts were expressed as $\mathrm{mg}$ of gallic acid equivalents per gram of dry weight ( $\mathrm{mg}$ GAE/g DW), through a calibration curve with gallic acid. All samples were analysed in six replicates.

\section{RP-HPLC evaluation of phenolic compounds from seed extracts}

Diluted samples from P. anisum seeds were injected to RPHPLC. The separation of phenolics was performed with an Agilent 1100 series HPLC system equipped with on-line degasser (G 1322A), quaternary pump (G 1311A), a thermostatic auto sampler (G 1313A), column heater (G 1316A) and diode array detector (G 1315A). Instrument control and data analysis were carried out using Agilent HPLC Chemstation 10.1 edition through Windows 2000. The separation was carried out on a reverse phase ODS C18 $(4 \mu \mathrm{m}, 2509$ $4.6 \mathrm{~mm}$, Hypersil) column used as stationary phase at ambient temperature. The mobile phase consisted of acetonitrile (solvent A) and water sulphuric acid (0.2\%) (solvent B). The flow rate was kept at $0.5 \mathrm{~mL} \mathrm{~min}^{-1}$. The gradient program was as follows: $15 \mathrm{~A} / 85 \%$ B 0-12 min, $40 \% \mathrm{~A} / 60 \%$
B $12-14 \min , 60 \%$ A/40\% B $14-18$ min, $80 \%$ A/20\% B 18-20 min, 90\% A/10\% B 20-24 min, 100\% A 24-28 min. The injection volume was $20 \mu \mathrm{L}$ and peaks were monitored at $280 \mathrm{~nm}$. Peak identification was obtained comparing the retention time and the UV spectra of the P. anisum phenolics chromatogram with those of pure standards which were purchased from Sigma (St. Louis, MO, USA). Analyses were performed in triplicates.

\section{Antioxidant activity of essential oils and extracts from aniseeds}

\section{DPPH radical scavenging assay}

Radical-scavenging activity was determined according to Hanato et al. [16]. Two millilitres of each extract and essential oil at different concentrations were added to $0.5 \mathrm{~mL}$ of a $0.2 \mathrm{mM}$ DPPH methanolic solution. After shaking, the mixture was incubated at room temperature in the dark for $30 \mathrm{~min}$, and then the absorbance was measured at $517 \mathrm{~nm}$. BHT was used as positive reference while methanol was used as negative reference. DPPH radical-scavenging activity was expressed as the inhibition percentage (I \%) and was calculated using the following formula:

$\mathrm{I} \%=100 \times($ Ablank - Asample $) /$ Ablank

where Ablank is the absorbance of the control at $30 \mathrm{~min}$ reaction (containing all reagents except the test compound), and Asample is the absorbance of the sample at $30 \mathrm{~min}$. Antiradical activity was expressed as IC50, defined as the concentration of the extract generating 50\% inhibition.

\section{Chelating effect on ferrous ions}

The ferrous ion chelating activity of different organ extracts and essential oils was assessed as described by Zhao et al. [17]. Different concentrations of the sample were added to $0.05 \mathrm{~mL}$ of $\mathrm{FeCl}_{2-} 4 \mathrm{H}_{2} \mathrm{O}$ solution $(2 \mathrm{mM})$ and left for incubation at room temperature for $5 \mathrm{~min}$. Then, the reaction was initiated by adding $0.1 \mathrm{~mL}$ of ferrozine $(5 \mathrm{mM})$, and the mixture was adjusted to $3 \mathrm{~mL}$ with deionized water, shaken vigorously and left standing at room temperature for $10 \mathrm{~min}$. Absorbance of the solution was then measured spectrophotometrically at $562 \mathrm{~nm}$. The percentage of inhibition of ferrozine- $\mathrm{Fe}^{2+}$ complex formation was calculated using the formula given below:

Metal chelating effect $(\%)=\left[\left(\mathrm{A}_{0}-\mathrm{A}_{1}\right) / \mathrm{A}_{0}\right] \times 100$ where $\mathrm{A}_{0}$ is the absorbance of the ferrozine- $\mathrm{Fe}^{2+}$ complex and $\mathrm{A}_{1}$ is the absorbance of the test compound. Results were expressed as $\mathrm{IC}_{50}$, efficient concentration corresponding to $50 \%$ ferrous iron chelating. EDTA was used as a positive control. Samples were analyzed in six replicates.
206

207

208

209

210

211

212

213

214

215

216

217

218

219

220

221

223

224

225

226

227

228

229

230

231

232

233

234

235

\begin{tabular}{|l|l|l|l|l|}
\hline Journal : Large 11694 & Article No : 284 & Pages : 9 & MS Code : 284 & Dispatch : 4-10-2019 \\
\hline
\end{tabular}




\section{Reducing power}

The method of Oyaizu [18] was used to assess the reducing power of different seed extracts. $1 \mathrm{~mL}$ of different concentrations of each extract and essential oil in acetone $80 \%$ were mixed with $2.5 \mathrm{~mL}$ of a $0.2 \mathrm{M}$ sodium phosphate buffer (pH 6.6) and $2.5 \mathrm{~mL}$ of $1 \%$ potassium ferricyanide $\left(\mathrm{K}_{3} \mathrm{Fe}\right.$ $\left.(\mathrm{CN})_{6}\right)$, and incubated in a water bath at $50{ }^{\circ} \mathrm{C}$ for $20 \mathrm{~min}$. Then, $2.5 \mathrm{~mL}$ of $10 \%$ trichloroacetic acid were added to the mixture that was centrifuged at $650 \times g$ for $10 \mathrm{~min}$. The supernatant $(2.5 \mathrm{~mL})$ was then mixed with $2.5 \mathrm{~mL}$ distilled water and $0.5 \mathrm{~mL}$ of $0.1 \%$ ferric chloride solution. The intensity of the blue-green colour was measured at $700 \mathrm{~nm}$. The $\mathrm{EC}_{50}$ value $(\mathrm{mg} / \mathrm{mL})$ is the extract concentration at which the absorbance was 0.5 for the reducing power and was calculated from the graph of absorbance at $700 \mathrm{~nm}$ against extract concentration. Ascorbic acid was used as a positive control.

\section{Statistical analysis}

Data were subjected to statistical analysis using statistical program package STATISTICA. Analysis of variance (ANOVA) followed by Duncan's multiple comparison test $(\mathrm{p}<0.05)$ were used.

\section{Results and discussion}

\section{Effect of drying methods on the essential oil yield and composition}

The changes of essential oil yield during drying process depended on the kind of tissue temperature, time and drying manner [19]. Thus, Fig. 1 presents the effects of drying methods on the essential oil content of aniseeds as expressed on the basis of dry weight. Our results showed that oil yields were considerably $(\mathrm{p}<0.05)$ affected by the dry methods.

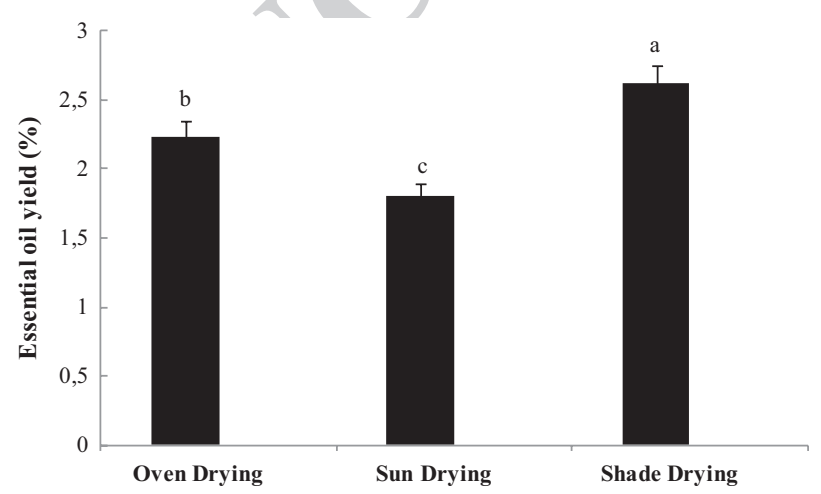

Fig. 1 Effects of drying methods on the essential oil yield (\%) of anise seeds. Oil yield values with different subscript $(\mathbf{a}-\mathbf{c})$ were significantly different at $\mathrm{p}<0.05$ (means of six replicates)
Therefore, shade drying seeds showed the highest oil content $(2.62 \%)$ whereas the sun drying seeds afforded the lowest oil yield which was of $1.80 \%$. Besides, oven drying seeds were characterized by an appreciable essential oil yield $(2.23 \%)$. These results are in line with those reported by Ozdemir et al. [20] who founded that the maximum oil yield of Origanum species was obtained with shade drying followed by oven drying method and that the sun drying plants offered the lowest essential oil yield. Also, similar results have been found on Hedge nettle plant [21]. In the case of cumin (Cuminum cyminum) seeds, Guo et al. [22] reported a decrease in the oil yield obtained with the oyen drying by of $24.4 \%$ compared to the air drying oil seeds $(4.9 \%)$. Above and beyond, in a study carried out on Coriandrum sativum, results showed that essential oil content in shade dried sample was higher than other drying methods [23]. Also, these authors explained that hot temperature had considerable effect on oil content due to the low boiling point of some components of the essential oil which led to their evaporation. Furthermore, Saeidi et al. [24] demonstrated that essential oil yield of Mentha longifolia was significantly affected by the drying method used and that the shade and oven drying showed the highest essential oil content while sun drying resulted in the lowest essential oil content. Consequently, in the shade drying method, low temperature reduces the loss of aromatic compounds in the atmosphere and preserved more essential oil compared with other treatments [4]. According to Hamrouni Sellami et al. [3], air drying at ambient temperature is the most efficient method to obtain the highest yield of bay laurel essential oil yield. Quite the opposite with the results explained beyond, some data reported an enhancement in the oil yield of several aromatic plants under hot drying temperature [25, 26]. For instance, the highest essential oil yield (2.8\%) of Origanum majorana was detected with drying in oven as compared with oil seeds obtained by the shade and sun drying methods (2.5 and 2.4\%, respectively) [27]. These variations can be due to the discrepancy between plant species and the localization of the secretory glands of medicinal herb [3].

Then again, drying methods had a significant effect on chemical composition of anise essential oil (Table 1). In total, $96.75 \%, 93.75 \%$ and $98.64 \%$ of the total amount for oven drying, sun drying and shade drying samples, in that order. Among treatment, trans-anethole was found as the main component, followed by estragole, $\gamma$-himachalene and $p$-anisaldehyde which meet the demand of the European Pharmacopeia [28]. Although the presence of these compounds has been previously reported by several authors $[10,13,29,30]$, their contents were considerably varied due to the application of different drying method, probably because of many biochemical processes (oxidation, glycoside hydrolysis, esterification, etc.) [1]. Results of the present study showed that the highest trans-anethole proportion $\mathbf{A Q}$ 
Table 1 Chemical composition of essential oils (\%) in Pimpinella anisum seeds as affected by drying treatments

\begin{tabular}{llllll}
\hline Compounds & \multicolumn{4}{l}{ \% of total volatiles } & \\
\cline { 2 - 6 } & $\mathrm{RI}^{\mathrm{a}}$ & $\mathrm{RI}^{\mathrm{b}}$ & Oven drying & Sun drying & Shade drying \\
\hline Terpene hydrocarbons & & & $0.10^{\mathrm{c}}$ & $2.02^{\mathrm{a}}$ & $1.04^{\mathrm{b}}$ \\
Linalool & 1097 & 1557 & $0.10 \pm 0.01^{\mathrm{c}}$ & $2.02 \pm 0.00^{\mathrm{a}}$ & $1.04 \pm 0.00^{\mathrm{b}}$ \\
Oxygenated monoterpene & & & $0.14^{\mathrm{b}}$ & $2.01^{\mathrm{a}}$ & $0.03^{\mathrm{b}}$ \\
$\alpha$-Terpinene & 1018 & 1249 & $0.14 \pm 0.03^{\mathrm{b}}$ & $2.01 \pm 0.00^{\mathrm{a}}$ & $0.03 \pm 0.00^{\mathrm{b}}$ \\
Phenylpropanoids & & & $88.43^{\mathrm{b}}$ & $80.94^{\mathrm{c}}$ & $93.89^{\mathrm{a}}$ \\
Anisole & 918 & 1720 & $1.08 \pm 0.88^{\mathrm{b}}$ & $0.74 \pm 0.04^{\mathrm{c}}$ & $2.52 \pm 0.01^{\mathrm{a}}$ \\
Estragole & 1197 & 1430 & $3.79 \pm 0.23^{\mathrm{a}}$ & $0.62 \pm 0.62^{\mathrm{b}}$ & $3.82 \pm 0.93^{\mathrm{a}}$ \\
trans-Anethole & 1253 & 1740 & $80.29 \pm 1.29^{\mathrm{b}}$ & $77.38 \pm 1.74^{\mathrm{c}}$ & $84.21 \pm 2.74^{\mathrm{a}}$ \\
p-Anisaldehyde & 1250 & 1718 & $3.15 \pm 0.37^{\mathrm{a}}$ & $1.05 \pm 0.31^{\mathrm{b}}$ & $3.10 \pm 0.02^{\mathrm{a}}$ \\
cis-Isoeugenol & 1359 & 2180 & $0.12 \pm 0.03^{\mathrm{b}}$ & $1.15 \pm 0.02^{\mathrm{a}}$ & $0.24 \pm 0.01^{\mathrm{b}}$ \\
Sesquiterpene hydrocarbons & & & $8.08^{\mathrm{a}}$ & $8.60^{\mathrm{a}}$ & $3.50^{\mathrm{b}}$ \\
$\beta$-Elemene & 1388 & 1465 & $0.12 \pm 0.01^{\mathrm{b}}$ & $0.59 \pm 0.01^{\mathrm{a}}$ & $0.07 \pm 0.01^{\mathrm{b}}$ \\
$\gamma$-Himachalene & 1484 & 1690 & $3.45 \pm 0.42^{\mathrm{a}}$ & $2.45 \pm 0.63^{\mathrm{b}}$ & $2.11 \pm 0.03^{\mathrm{bc}}$ \\
Zingiberene & 1494 & 1672 & $0.09 \pm 0.01^{\mathrm{b}}$ & $0.25 \pm 0.02^{\mathrm{a}}$ & $0.38 \pm 0.02^{\mathrm{a}}$ \\
$\beta$-Himachalene & 1505 & 1942 & $1.04 \pm 0.01^{\mathrm{a}}$ & $1.08 \pm 0.00^{\mathrm{a}}$ & $0.10 \pm 0.01^{\mathrm{b}}$ \\
$\beta$-Bisabolene & 1506 & 1832 & $2.23 \pm 0.01^{\mathrm{a}}$ & $1.64 \pm 0.01^{\mathrm{b}}$ & $0.75 \pm 0.03^{\mathrm{c}}$ \\
Isolongifolene & 1532 & 2003 & $1.07 \pm 0.02^{\mathrm{b}}$ & $1.53 \pm 0.01^{\mathrm{a}}$ & $0.03 \pm 0.00^{\mathrm{c}}$ \\
Diepi- $\alpha$-cedrene & 1575 & 2020 & $0.08 \pm 0.01^{\mathrm{b}}$ & $1.06 \pm 0.01^{\mathrm{a}}$ & $0.06 \pm 0.02^{\mathrm{b}}$ \\
Total identified & & & 96.75 & 93.57 & 98.46 \\
\hline
\end{tabular}

Compounds are listed in order of elution in polar column (HP-Innowax)

$R I^{\mathrm{a}}, R I^{\mathrm{b}}$ retention indices calculated using respectively an apolar column (HP-5) and a polar column (HPinnowax); $R I$ retention indice; values followed by the same small letter did not share significant differences at $\mathrm{p}<0.05$ (Duncan test) was obtained by the shade drying method $(84.21 \%)$. Its lowest $(77.38 \%)$ was observed with sun drying process. Trans-anethole has a sweet herbaceous odor, sweet taste and was largely used as a substrate for synthesis of various pharmaceutical substances [31]. Although, estragole, the second main compound of the EO, was found at the highest level in the shade and oven drying samples $(3.82 \%$ and $3.79 \%$ ) respectively. The uppermost $\gamma$-himachalene content belonged to the oven drying seeds. However and in the case of minor compounds, sun drying process enhanced considerably the proportions of linalool, $\alpha$-terpinene, $c i s$-isoeugenol and diepi- $\alpha$-cedrene in the EO, which reached 2.02, 2.01, 1.15 and $1.06 \%$, respectively, in comparison to oven and shade process.

Independently of the dry treatment, the EO compounds were grouped in four chemical classes according to their functional groupings. Without a doubt, phenylpropanoides were represented in high amount, followed by sesquiterpene hydrocarbons. On the other hand, oxygenated and terpenic hydrocarbons were the minor class in aniseed essential oil. The ratios of these compounds are significantly affected by the method of drying $(\mathrm{p}<0.05)$. In this way, our results indicated that sunlight and oven techniques (high temperature drying methods) significantly reduced the proportions of phenylpropanoide class (80.94 and $88.43 \%$ ), correspondingly, in comparison to shade drying process (93.89\%). Moreover, as compared to shade drying, oven and sun drying methods seem to be the methods that increased twofold the sesquiterpene hydrocarbons fractions ( 8.08 and $8.60 \%$ respectively). As stated by Hamrouni Sellami et al. [3], the effect of the drying method on the maintenance or the loss of volatiles in spices is relied on the nature of plant and the concerned component. In summary, drying in the shade resulted in significant increase in the concentration of most of the main compounds such as trans-anethole, estragole and anisole.

Nevertheless, shade drying would seem to be the best and the more advisable method which is simple inexpensive and help to conserve the characteristic aroma of aniseed essential oil.

\section{Effect of drying on phenolic and flavonoid contents and composition}

Quantitative evaluation of total phenolics in different seed extracts as estimated by the method of Folin-Ciocalteu revealed that aniseeds exhibited considerable and variable contents ranging from 31.15 to $42.70 \mathrm{mg}$ of $\mathrm{GAE} / \mathrm{g}$ of DM (Fig. 2). The highest total phenolic content (TPC) was traced in shade drying seed extracts and was 1.4 times

\begin{tabular}{|l|l|l|l|l|}
\hline Journal : Large 11694 & Article No : 284 & Pages : 9 & MS Code : 284 & Dispatch : 4-10-2019 \\
\hline
\end{tabular}




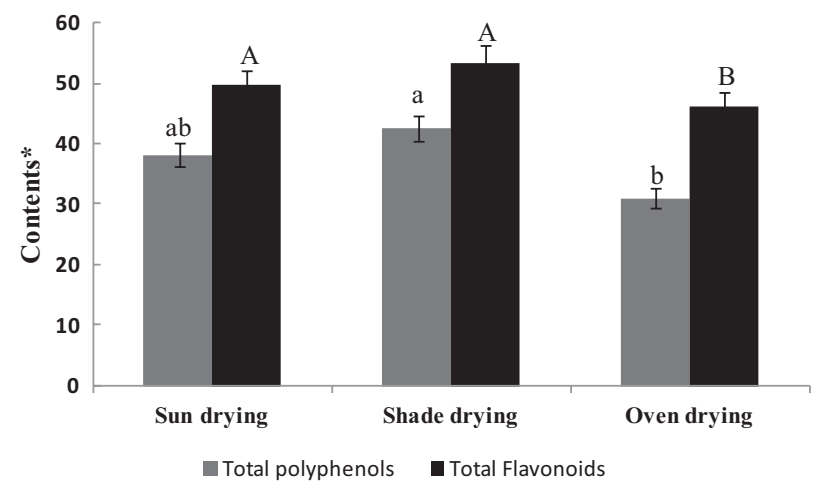

Fig. 2 Total phenolic (mg GAE/g DM) and flavonoid (mg CE/g DM) contents of anise (Pimpinella anisum) seed extracts as affected by drying methods. Values are means of six replications $(\mathrm{N}=6 \pm \mathrm{SD})$; $G A E$ gallic acid equivalent; $C E$ catechin equivalents. Total phenolic contents marked with different small letters or total flavonoid contents marked with different capital letters share significant differences at $\mathrm{p}<0.05$ (Duncan's test)

higher than those of oven drying ones. Alternatively, total flavonoid contents (TFC) as measured according to the method of Dewanto et al. [15] were of $46.20 \mathrm{mg}$ of QE/g of DM) in oven dried seeds and they increased slightly in the cases of shade drying and sun drying seed extracts (53.55 and $49.74 \mathrm{mg}$ of QE/g of DM). From our results, it can be observed that temperature (sun or oven) had an important effect on the total phenolic content which results in a drop in these components. Our results were consistent basically with previous findings by Miranda et al. [32]. These authors state that the losses of TPC due to thermal degradation may be due to the bindings of polyphenols with other components or the alteration in the chemical structure of polyphenols which cannot be extracted and determined by available methods. Generally, drying of plant material could result in a decrease or in an increase of the TPC. In the case of coriander leaves, Hihat et al. [33] reported that the temperature of oven drying had a significant influence on TPC and that the highest TPC, which was reached at $60^{\circ} \mathrm{C}$, decreased in high temperatures $\left(100^{\circ} \mathrm{C}\right)$. In another investigation, Śledź et al. [6] stated that herbs species had significant influence on phenolic contents. Accordingly, the lowest degradation of polyphenols was observed for herbs from Apiaceae family (parsley lovage) followed by Brassicacaeae and Lamiaceae.

As mentioned by Hihat et al. [33], the loss of macromolecules like flavonoids during heat treatment might be due to the harsh drying conditions, in particular, the temperature and duration used. Additionally, Tan et al. [34] showed that the primary factor that caused a decrease in TPC of air-dried mulberry leaves was oxidative enzymes, whereas the reduction in TPC of sun-dried and oven dried leaves was caused mainly by thermal degradation. On the contrary, high temperatures might generate an increase in the phenolic content where cereals were investigated [35]. Considering the results from this investigation, it is worth mentioning that shade drying is suitable for enhancing the extractability of phenolic compounds to a great extent, but their efficacy is dependent on the nature of the vegetal matrix being used and the type of compounds to be extracted [36].

Qualitative and quantitative composition of phenolics varied significantly $(\mathrm{p}<0.05)$ with the method used for drying. As it can be seen in Table 2 flavonoids predominated in the three types of dried seeds. The contents of flavonoids ranged from $8.56 \mathrm{mg} / \mathrm{g}$ DM to $10.25 \mathrm{mg} / \mathrm{g} \mathrm{DM}$ and increased in the following order oven drying $<$ sun drying $<$ shade drying. As for phenolic acids, their contents ranged from $5.66 \mathrm{mg} / \mathrm{g}$ DM to $9.32 \mathrm{mg} / \mathrm{g} \mathrm{DM}$ and increased in the following order oven drying $<$ sun drying $<$ shade drying. The highest content of phenolic compounds by RP-HPLC was found in shade drying seeds (19.71 mg/g DM) followed by sun and oven drying seeds (17.93 and $14.22 \mathrm{mg} / \mathrm{g}$ DM). Analogous results were described by Multari et al. [36] who reported that oven drying caused degradation of the free phenolic acids, and drying in shade resulted in relatively high concentrations in phenolic compounds of quinoa seeds. According to these results, the contents of phenolic compounds as assessed by RP-HPLC are significantly too inferior to those obtained by the Folin-Ciocalteu method at $\mathrm{p}<0.05$. These differences could be explained by the weak selectivity of the Folin-Ciocalteu reagent, as it reacts positively with different antioxidant compounds [37]. It appear that some phenolic compounds decompose rapidly in direct sunlight or if dried at elevated temperature [15]. In fact, Choi et al. [38] reported that temperature might disrupt the cell wall and liberate phenolic compounds from the insoluble portion of the plant.

As can be seen in Table 2, our results showed also that drying aniseeds looked to influence acutely phenolic composition by increasing contents of some compounds and also decreasing those of others. Thus, a total of 12 phenolic compounds were identified in all extracts. Naringin was the major phenolic compound in all the extracts and representing, respectively, 42.21, 41.04 and $43.76 \%$ for sun, shade and oven drying process followed by chlorogenic acid (23.13-27.19\%) and rosmarinic acid (12.26-15.95\%) in all samples. Similarly, Bettaieb Rebey et al. [13] reported that naringin was the main phenolic compound of aniseed extract. Naringin is a flavanone glycoside found in grapes and citrus fruits and it is known as a strong antioxidant and scavenger of free radicals [39]. Results from the current study show that the highest concentration of phenolic compounds was obtained when aniseeds were dried at shade and this can be considered when searching for an optimum drying process of $P$. anisum seeds. 
Table 2 Effect of drying methods on phenolic contents (micrograms per gram DM) and composition (percent) of Pimpinella anisum L. extracts

\begin{tabular}{|c|c|c|c|c|c|c|}
\hline & \multicolumn{2}{|l|}{ Sun drying } & \multicolumn{2}{|l|}{ Shade drying } & \multicolumn{2}{|l|}{ Oven drying } \\
\hline & $\mathrm{mg} / \mathrm{g}$ & $\%$ & $\mathrm{mg} / \mathrm{g}$ & $\%$ & $\mathrm{mg} / \mathrm{g}$ & $\%$ \\
\hline Phenolic acid & 7.68 & 44.83 & 9.32 & 45.73 & 5.66 & 39.78 \\
\hline Gallic acid & $0.01 \pm 0.00^{\mathrm{a}}$ & $0.05 \pm 0.01^{\mathrm{B}}$ & $0.06 \pm 0.00^{\mathrm{a}}$ & $0.30 \pm 0.00^{\mathrm{A}}$ & $0.01 \pm 0.00^{\mathrm{a}}$ & $0.07 \pm 0.01^{\mathrm{B}}$ \\
\hline Chlorogenic acid & $3.99 \pm 0.01^{\mathrm{b}}$ & $24.25 \pm 0.22^{\mathrm{B}}$ & $5.36 \pm 0.00^{\mathrm{a}}$ & $27.19 \pm 0.00^{\mathrm{A}}$ & $3.29 \pm 0.01^{\mathrm{b}}$ & $23.13 \pm 0.22^{\mathrm{B}}$ \\
\hline Syringic acid & $0.63 \pm 0.01^{\mathrm{a}}$ & $3.51 \pm 0.08^{\mathrm{A}}$ & $0.25 \pm 0.00^{\mathrm{b}}$ & $1.26 \pm 0.00^{\mathrm{B}}$ & $0.11 \pm 0.01^{\mathrm{b}}$ & $0.77 \pm 0.08^{\mathrm{B}}$ \\
\hline$p$-Coumaric acid & $0.53 \pm 0.00^{\mathrm{a}}$ & $2.95 \pm 0.01^{\mathrm{A}}$ & $0.02 \pm 0.00^{\mathrm{C}}$ & $0.63 \pm 0.00^{\mathrm{a}}$ & $0.20 \pm 0.00^{\mathrm{b}}$ & $1.40 \pm 0.01^{\mathrm{B}}$ \\
\hline Rosmarinic acid & $2.20 \pm 0.01^{\mathrm{b}}$ & $12.26 \pm 0.01^{\mathrm{B}}$ & $3.15 \pm 0.00^{\mathrm{a}}$ & $15.95 \pm 0.00^{\mathrm{A}}$ & $2.03 \pm 0.01^{\mathrm{b}}$ & $14.27 \pm 0.01^{\mathrm{A}}$ \\
\hline Ellargic acid & $0.32 \pm 0.01^{\mathrm{a}}$ & $1.78 \pm 0.01^{\mathrm{A}}$ & $0.08 \pm 0.00^{\mathrm{b}}$ & $0.40 \pm 0.00^{\mathrm{B}}$ & $0.02 \pm 0.01^{\mathrm{b}}$ & $0.14 \pm 0.01^{\mathrm{B}}$ \\
\hline Flavonoids & 10.25 & 54.79 & 11.32 & 54.27 & 8.56 & 59.41 \\
\hline Epicatechin-3-Ө-gallate & $0.24 \pm 0.01^{\mathrm{a}}$ & $1.33 \pm 0.02^{\mathrm{A}}$ & $0.18 \pm 0.00^{\mathrm{b}}$ & $0.91 \pm 0.00^{\mathrm{B}}$ & $0.14 \pm 0.01^{\mathrm{b}}$ & $0.98 \pm 0.02^{\mathrm{B}}$ \\
\hline Coumarin & $0.69 \pm 0.01^{\mathrm{ab}}$ & $3.84 \pm 0.01^{\mathrm{B}}$ & $0.88 \pm 0.00^{\mathrm{a}}$ & $4.46 \pm 0.00^{\mathrm{A}}$ & $0.64 \pm 0.01^{\mathrm{b}}$ & $4.50 \pm 0.01^{\mathrm{A}}$ \\
\hline Rutin & $0.22 \pm 0.02^{\mathrm{a}}$ & $1.22 \pm 0.05^{\mathrm{A}}$ & $0.27 \pm 0.00^{\mathrm{a}}$ & $1.36 \pm 0.00^{\mathrm{A}}$ & $0.12 \pm 0.02^{b}$ & $0.84 \pm 0.05^{\mathrm{B}}$ \\
\hline Quercetin & $0.51 \pm 0.03^{\mathrm{a}}$ & $0.51 \pm 0.02^{\mathrm{C}}$ & $0.49 \pm 0.00^{\mathrm{a}}$ & $2.40 \pm 0.00^{\mathrm{B}}$ & $0.51 \pm 0.03^{\mathrm{a}}$ & $3.58 \pm 0.02^{\mathrm{A}}$ \\
\hline Naringin & $7.57 \pm 0.03^{\mathrm{a}}$ & $42.21 \pm 0.01^{\mathrm{A}}$ & $8.09 \pm 0.00^{\mathrm{a}}$ & $41.04 \pm 0.00^{\mathrm{AB}}$ & $6.21 \pm 0.03^{\mathrm{b}}$ & $43.76 .12 \pm 0.01^{\mathrm{A}}$ \\
\hline Apigenin & $0.77 \pm 0.00^{\mathrm{a}}$ & $4.29 \pm 0.01^{\mathrm{A}}$ & $0.75 \pm 0.00^{\mathrm{a}}$ & $3.80 \pm 0.00^{\AA}$ & $0.57 \pm 0.00^{\mathrm{a}}$ & $4.00 \pm 0.01^{\mathrm{A}}$ \\
\hline NI & $0.25 \pm 0.01^{\mathrm{a}}$ & $1.39 \pm 0.03^{\mathrm{A}}$ & $0.06 \pm 0.00^{\mathrm{b}}$ & $0.30 \pm 0.00^{\mathrm{B}}$ & $0.25 \pm 0.01^{\mathrm{a}}$ & $1.75 \pm 0.03^{\mathrm{A}}$ \\
\hline Total & 17.93 & 100 & 19.71 & 100 & 14.22 & 100 \\
\hline
\end{tabular}

Values are given as means of six replicates \pm SD. Values followed by the same small or capital superscript letter did not share significant differences at $\mathrm{p}<0.05$ (Duncan's test)

$D M$ dry matter

\section{Effect of drying on antioxidant activities of anise essential oil and extracts}

The most widely used synthetic antioxidants in food (butylated hydroxytoluene BHT, butylated hydroxyanisole BHA) are very effective in their role as antioxidants. However, their use in food products has led to the appearance of remarkable side effects [40]. For this reason, there is a growing interest in the studies of natural healthy (nontoxic) additives as potential antioxidants [41].
In our study, DPPH radical scavenging assay, reducing power and chelating ability were used to assess the antioxidant activity of anise essential oils and extracts as obtained by drying methods. Thus, Table 3 shows that all the studied samples were able to scavenge the DPPH free radical in different levels. Shade dried samples gave the highest radical scavenging activity with an $\mathrm{IC}_{50}$ value of $10.15 \mu \mathrm{g} / \mathrm{mL}$ and $114.87 \mu \mathrm{g} / \mathrm{mL}$, respectively, for extracts and essential oils, while the lowest activity was recorded in samples of oven dried seeds with an $\mathrm{IC}_{50}$ of $43.84 \mu \mathrm{g} / \mathrm{mL}$ and $287.56 \mu \mathrm{g} / \mathrm{mL}$ in that order. What's more our results

Table 3 Antioxidant activities of Pimpinella anisum L. essential oils and extracts as affected by drying methods

\begin{tabular}{|c|c|c|c|c|c|c|c|c|c|}
\hline & \multicolumn{3}{|l|}{ Extracts } & \multicolumn{3}{|l|}{ Essential oils } & \multicolumn{3}{|c|}{ Synthetic antioxidants } \\
\hline & Sun drying & Shade drying & Oven drying & Sun drying & Shade drying & Oven drying & BHT & EDTA & Ascorbic acid \\
\hline $\begin{array}{l}\text { DPPH } \\
\text { assay } \\
(\mathrm{IC} 50 \mu \mathrm{g} / \\
\mathrm{mL})\end{array}$ & $31.97 \pm 0.02^{\mathrm{b}}$ & $10.15 \pm 0.05^{\mathrm{a}}$ & $43.84 \pm 0.11^{\mathrm{c}}$ & $125.49 \pm 0.56^{\mathrm{b}}$ & $114.87 \pm 0.42^{\mathrm{a}}$ & $287.56 \pm 0.45^{\mathrm{c}}$ & $24.30 \pm 0.03$ & - & - \\
\hline $\begin{array}{l}\text { Reducing } \\
\text { power } \\
\text { assay } \\
(\mathrm{EC} 50 \mu \mathrm{g} / \\
\mathrm{mL})\end{array}$ & $294.11 \pm 0.28^{\mathrm{b}}$ & $187.24 \pm 0.41^{\mathrm{a}}$ & $340.87 \pm 0.09^{\mathrm{bc}}$ & $567.28 \pm 0.01^{\mathrm{a}}$ & $548.05 \pm 0.55^{\mathrm{a}}$ & $603.85 \pm 0.82^{\mathrm{b}}$ & - & - & $41.65 \pm 0.21$ \\
\hline $\begin{array}{l}\text { Chelating } \\
\text { ability } \\
\text { (IC50 mg/ } \\
\text { mL) }\end{array}$ & $9.04 \pm 0.02^{b}$ & $6.85 \pm 0.01^{\mathrm{a}}$ & $10.24 \pm 0.03^{b}$ & $63.23 \pm 0.02^{\mathrm{b}}$ & $58.65 \pm 0.16^{\mathrm{a}}$ & $70.12 \pm 0.78^{c}$ & - & $0.04 \pm 0.01$ & \\
\hline
\end{tabular}

Values are given as means of three replicates \pm standard deviation. Means followed by the same superscript letters within the same column are not significantly different at $\mathrm{p}<0.05$ based on Duncan's multiple range test

\begin{tabular}{|l|l|l|l|l|}
\hline Journal : Large 11694 & Article No : 284 & Pages : 9 & MS Code : 284 & Dispatch : 4-10-2019 \\
\hline
\end{tabular}


showed that shade drying extracts showed a radical scavenging activity stronger than that of BHT $\left(\mathrm{IC}_{50}=24.30 \mu \mathrm{g} /\right.$ $\mathrm{mL}$ ).

The effect of drying method on the antioxidant ability of extract and essential oil from aniseeds has been also assessed by ferric-reducing power estimation (Table 3). Results showed that all the tested samples presented a weak reducing activity as compared with that of ascorbic acid $\left(\mathrm{EC}_{50}=41.65 \mu \mathrm{g} / \mathrm{mL}\right)$. The highest power was found in shade drying plants $\left(\mathrm{EC}_{50}=187.24\right.$ and $\left.548.05 \mu \mathrm{g} / \mathrm{mL}\right)$ where the lowest power was observed in oven dried samples $\left(\mathrm{EC}_{50}=340.87\right.$ and $603.85 \mu \mathrm{g} / \mathrm{mL}$ ), in the same way, for extracts and essential oils. We should point out that despite the relatively high values of $\mathrm{EC}_{50}$ as compared to that of ascorbic acid, dried aniseed extracts were able to reduce $\mathrm{Fe}^{3+}$ ion in the reaction medium. As for reducing power, results showed that all the samples displayed the same tendency for the chelating ability and presented an infirm activity as compared with that of EDTA $\left(\mathrm{IC}_{50}=0.04 \mathrm{mg} / \mathrm{mL}\right)$. The overhead power was traced at shade drying process for both extracts and essential oils ( 6.85 and $58.65 \mathrm{mg} / \mathrm{mL}$ ), respectively. Our result was in concordance with that reported by Hihat et al. [33] who observed that temperature led to the decrease in antioxidant activity of coriander (Coriandrum sativum) leaf extracts. Generally, sun drying exposes herbs to unpredictable weather conditions. In the case of Vitex negundo and Vitex trifolia, samples were subjected to sun drying at a mild temperature of $38.8^{\circ} \mathrm{C}$; however, there was a huge reduction in antioxidant activity compared to oven drying [42]. The reduced antioxidant activity of sun-dried samples compared to oven drying at $50{ }^{\circ} \mathrm{C}$ was also detected in the drying of mulberry leaves [34].

It was also observed that regardless of the inability of the aniseed extract and essential oil to compete with the positive controls (ascorbic acid in iron reducing and EDTA in iron chelating), these extracts did possess mild antioxidant activities and may be considered as potential preservatives for food utilization where aniseeds were preferred due to its safety.

Little information are available on the effect of drying on the antioxidant activity of plant essential oil. Hence, it was reported that the scavenging activity of cumin (Cuminum cyminum) essential oil on DPPH radicals was far lower than that of standard Trolox and significantly influenced by drying methods and conditions [22]. Generally, the antioxidant potencies of plant essential oil were attributable to their chemical composition. Thus, the weak antioxidant properties found for the aniseed essential oil samples dried with different methods may be attributed primarily to their composition. Finally, the obtained results in the present study demonstrated that there is a proportional relationship between drying conditions and both antioxidant compounds and antioxidant capacity.

\section{Conclusion}

In this study, results clearly indicated that shade drying method would seem to be the best and the more advisable method to conserve the characteristic aroma of aniseedAQ5 4 essential oil. Moreover, shade drying is the more suitable method to keep the high total phenol and total flavonoid contents to enhance the antioxidant potency of aniseed extract. Shade drying could be considered if small quantities of products are to be dried or when economic constraints exist. In brief, these results suggested that this technique is candidate of great potential to be considered by grain drying producers to formulate foods richer in bioactive phytochemicals.

\section{Compliance with ethical standards}

Conflict of interest The authors declare that they have no conflict of interst.

\section{References}

1. M.V. Diaz-Maroto, E. Sánchez Palomo, L. Castro, G. Viñas, M.S. Perez-Coello, J. Sci. Food Agric. 84, 2070 (2004)

2. L.L. Zhang, S. Lv, J.G. Xuc, L.F. Zhang, Nat. Prod. Res. 32, 1184 (2018)

3. I.H. Sellami, W.A. Wannes, I. Bettaieb, S. Berrima, T. Chahed, B. Marzouk, Food Chem. 126, 691 (2011)

4. F. Mirhossein, M. Rahimmalek, A.G. Pirbalouti, M. Taghipoor, J. Essent. Oil Res. 27, 204 (2015)

5. H. Ayyobi, P. Gholam-Ali, O. Jamal-Ali, Ratar. Povrt. 51, 18 (2014)

6. M. Śledź, M. Nowacka, A. Wiktor, D. Witrowa-Rajchert, Food Bioprod. Process 91, 421 (2013)

7. H.P. Garg, J. Prakash, Solar Energy Fundamentals and Applications (Tata McGraw-Hill Publishing Company Limited, New Delhi, India, 2000), p. 434

8. I. Samojlik, V. Mijatović, S. Petković, B. Škrbić, B. Božin, Fitoterapia 83, $1466(2012)$

9. A. Özel, Exp. Agric. 45, 117 (2009)

10. H. Ullah, B. Honermeier, Ind. Crops Prod. 42, 489 (2013)

11. A.S. Tepe, B. Tepe, Ind. Crops Prod. 69, 153 (2015)

12. I. Bettaieb Rebey, S. Bourgou, W. Aidi Wannes, I. Hamrouni Selami, M. Saidani Tounsi, B. Marzouk, M.L. Fauconnier, R. Ksouri, Plant Biosyst. 152, 971 (2018)

13. I. Bettaieb Rebey, W. Aidi Wannes, S. Ben Kaab, S. Bourgou, M. Saidani Tounsi, R. Ksouri, M.L. Fauconnier, Sci. Hortic. 246, 453 (2019)

14. Y. Zaouali, S. Ammar, N. Kechiche, J. Jay, H. Ben Aissia, Eur. Phys. J. Appl. Phys. 52, 11302 (2010)

15. V. Dewanto, X. Wu, K.K. Adom, R.H. Liu, J. Agric. Food Chem. 50, 3010 (2002)

16. T. Hanato, H. Kagawa, T. Yasuhara, T. Okuda, Chem. Pharm. Bull. 36, 2090 (1998)

17. H. Zhao, J. Dong, J. Lu, J. Chen, Y. Li, Y. Shan, W. Fan, G. Gu, J. Agric. Food Chem. 54, 277 (2006)

18. M. Oyaizu, Jpn. J. Nutr. Diet. 44, 307 (1986) 
19. M.R. Dehghani Mashkani, K. Larijani, A. Mehrafarin, H. Naghdi Badi, Ind. Crops Prod. 112, 389 (2018)

20. N. Ozdemir, Y. Ozgen, M. Kiralan, A. Bayrak, N. Arslan, M. Fawzy Ramadan, J. Food Meas. Charact. 12, 820 (2017)

21. S. Hazrati, P. Farnia, F. Habibzadeh, S. Mollaei, J. Food Process. Preserv. 42, e13686 (2018)

22. Y.R. Guo, Y.-M. An, Y.-X. Jia, J.G. Xu, JEOP 21, 1 (2018)

23. A.G. Pirbalouti, S. Salehi, L. Craker, J. Appl. Res. Med. Aromat. Plant 4, 35 (2017)

24. K. Saeidi, G. Zohre, S. Rostami Hudson, JEOP 19, 391 (2016)

25. M.D. Castro, L.C. Ming, M.O.M. Marques, S.R. Machado, in Proceeding of the 5th National Symposium New Crops and New uses, (Atlanta, USA, 2001), p. 599

26. F. Sefidkon, K. Abbasi, G.B. Khaniki, Food Chem. 99, 19 (2006)

27. Z. Özer, T. Kiliç, S. Selvi, C. Pasa, TEOP 21, 1403 (2018)

28. European Pharmacopoeia, Dritter Nachtrag, 3rd edn (Council of Europe, Strasbourg, 2000), pp. 499-500

29. M. Acimovic, V. Tesevic, M. Todosijevic, J. Djisalov, S. Oljaca, Bot. Serb. 39, 9 (2015)

30. E. Fitsiou, G. Mitropoulou, K. Spyridopoulou, A. Tiptiri-Kourpeti, M. Vamvakias, H. Bardouki, M. Panayiotidis, A. Galanis, Y. Kourkoutas, K. Chlichlia, Molecules 21, 1069 (2016)

31. I. Kosalec, S. Pepeljnjak, D. Kustrak, Acta Pharm. 55, 377 (2017)

32. M.A. Miranda, J. Vega-Gálvez, G. López, M. Parada, M. Sanders, Ind. Crops Prod. 32, 258 (2010)
33. S. Hihat, H. Remini, K. Madani, Int. Food Res. J. 24, 503-509 (2017)

34. T.C. Tan, L.H. Cheng, R. Bhat, G. Rusul, A.M. Easa, Food Chem. 142, 121 (2015)

35. P. Van-Hung, Crit. Rev. Food Sci. Nutr. 56, 25 (2016)

36. S. Multari, J.M. Pihlava, P. Ollennu-Chuasam, V. Hietaniemi, B. Yang, J.P. Suomela, J. Agric. Food Chem. 66, 2900 (2018)

37. I. Bettaieb, I. Hamrouni-Sellami, S. Bourgou, F. Limam, B. Marzouk, Acta Physiol. Plant. 33, 1103 (2011)

38. Y. Choi, S.M. Lee, J. Chun, H.B. Lee, J. Lee, Food Chem. 99, 381 (2006)

39. M.A. Alam, N. Subhan, M.M. Rahman, S.J. Uddin, H.M. Reza, S.D. Sarker, Adv. Nutr. 5, 404 (2014)

40. A.H. Ebrahimabadi, E.H. Ebrahimabadi, Z. Djafari-Bidgoli, F.J. Kashi, A. Mazoochi, H. Batooli, Food Chem. 119, 452e458 (2010)

41. A. Tomaino, F. Cimino, V. Zimbalatti, V. Venuti, V. Sulfaro, A. DePasquale, Food Chem. 89, 549 (2005)

42. K.L. Chong, Y.Y. Lim, J. Food Qual. 35, 51 (2012)

Publisher's Note Springer Nature remains neutral with regard to jurisdictional claims in published maps and institutional affiliations.
609

610

611

612

613

614

615

616

617

618

619

620

621

622

623

624

625

626

627

628 629

630 


\begin{tabular}{|ll|}
\hline Journal: & $\mathbf{1 1 6 9 4}$ \\
Article: & $\mathbf{2 8 4}$ \\
\hline
\end{tabular}

\section{Author Query Form}

\section{Please ensure you fill out your response to the queries raised below and return this form along with your corrections}

Dear Author

During the process of typesetting your article, the following queries have arisen. Please check your typeset proof carefully against the queries listed below and mark the necessary changes either directly on the proof/online grid or in the 'Author's response' area provided below

\begin{tabular}{|l|l|l|}
\hline Query & Details Required & Author's Response \\
\hline AQ1 & $\begin{array}{l}\text { Author names: Please confirm if the author names are presented accurately and in the } \\
\text { correct sequence (given name, middle name/initial, family name). Author 1 Given } \\
\text { name: [Iness] Last name [Bettaieb Rebey], Author 3 Given name: [Sofiene] Last name } \\
\text { [Ben Kaab], Author 4 Given name: [Wissem] Last name [Aidi Wannes], Author 6 } \\
\text { Given name: [Moufida] Last name [Saidani Tounsi]. Also, kindly confirm the details in } \\
\text { the metadata are correct. }\end{array}$ & \\
\hline AQ2 & kindly check and confirm the processed country in affiliation 2 is correct. & \\
\hline AQ3 & Please confirm the section headings are correctly identified. & \\
\hline AQ4 & Kindly check and confirm that the tables have been renumbered. & \\
\hline AQ5 & Please check and confirm the processed jounal title for the reference 23 is correct. & \\
\hline
\end{tabular}

